\title{
Hypoxia-Induced Post-Translational Changes in Red Blood Cell Protein Map of Newborns
}

\author{
BARBARA MARZOCCHI, LUCIA CICCOLI, CHIARA TANI, SILVIA LEONCINI, VIVIANA ROSSI, \\ LUCA BINI, SERAFINA PERRONE, AND GIUSEPPE BUONOCORE \\ Department of Pediatrics, Obstetrics and Reproductive Medicine [B.M., C.T., S.P., G.B.], Department of \\ Molecular Biology [L.B.], Department of Pathophysiology, Experimental Medicine and Public Health \\ [L.C., S.L., V.R.], University of Siena, 53100 Siena, Italy
}

\begin{abstract}
Tyrosine (Tyr) phosphorylation is implicated in the modification of several erythrocyte functions, such as metabolic pathways and membrane transport, as well as in signal transduction systems. Here we describe the map of Tyr-phosphorylated soluble proteins of newborn red blood cells (RBC) using an in vitro model simulating $\mathrm{RBC}$ reoxygenation at birth after an intrauterine hypoxic event. We tested the hypothesis that a hypoxic environment and subsequent reoxygenation promote posttranslational changes in the RBC protein map of newborns, in addition to desferrioxamine (DFO)-chelatable iron (DCI) release and methemoglobin (MetHb) formation. Umbilical cord blood $\mathrm{RBC}$ were incubated under hypoxic conditions for $16 \mathrm{~h}$ at $37^{\circ} \mathrm{C}$, and subsequently for $8 \mathrm{~h}$ under aerobic conditions. Control erythrocytes were incubated under aerobic conditions at $37^{\circ} \mathrm{C}$ for the period of the experiment, i.e. for $24 \mathrm{~h}$. Tyr-phosphorylation proteins were assessed using advanced high-resolution twodimensional electrophoresis, 2-D immunoblot analysis with antiphosphotyrosine (anti-pTyr) antibodies, and computer-aided electrophoretogram analysis. Higher DCI release and MetHb formation were observed in newborn $\mathrm{RBC}$ incubated under hypoxic conditions than in those incubated aerobically. Different immunoreactivity patterns with anti-pTyr antibodies were also observed between newborn RBC incubated under hypoxic conditions and controls. A hypoxic environment is a factor promoting DCI release, a well-known condition of oxidative stress. This is the first map of Tyr-phosphorylated soluble proteins of new-
\end{abstract}

\section{ABSTRACT}

born $\mathrm{RBC}$ obtained using an in vitro model simulating $\mathrm{RBC}$ reoxygenation at birth after an intrauterine hypoxic event. Our results suggest that hypoxia increases Tyr-phosphorylation of antioxidant proteins, protecting RBC against oxidative stress. (Pediatr Res 58: 660-665, 2005)

AChE, acetylcholinesterase

\section{Abbreviations}

anti-pTyr, anti-phosphotyrosine

AOP2, antioxidant protein 2

BVR, biliverdin IX- $\beta$ reductase

DCI, desferrioxamine-chelatable iron

DFO, desferrioxamine

DTE, dithio-erythritol

FR, flavin reductase

G3PDH, glyceraldehyde 3-phosphate dehydrogenase

IPG, immobilized $\mathrm{pH}$ gradient

MetHb, methemoglobin

Prxs, peroxiredoxins

PTK, protein tyrosine kinase

RBC, red blood cells

ROS, reactive oxygen species

Tpx 1, thioredoxin peroxidase 1

Tyr, tyrosine

2-D, two-dimensional

2,3-DPG, 2,3-diphosphoglycerate
RBC are exposed to oxidative stress more than other cells of the body as a result of their high membrane polyunsaturated fatty acid content and high cellular concentrations of oxygen and heme iron. Iron plays a central role in generating harmful ROS. Its redox cycling promotes the Fenton reaction, which produces the potent oxidant hydroxyl radical (1). To be redoxcycling active, iron must be released from its macromolecular

Received October 18, 2004; accepted March 1, 2005.

Correspondence: Giuseppe Buonocore, M.D., Department of Pediatrics, Obstetrics and Reproductive Medicine, University of Siena, Policlinico Santa Maria alle Scotte, V.le Bracci 36, 53100 Siena, Italy; e-mail: buonocore@unisi.it

DOI: 10.1203/01.PDR.0000180545.24457.AC complexes (mainly transport and storage proteins) (2). We previously showed that iron is released from $\mathrm{Hb}$ in a DFOchelatable form when erythrocytes are exposed to oxidative stress, such as when they are incubated with oxidizing agents or undergo prolonged aerobic incubation, two models of erythrocyte ageing (3). Iron release is accompanied by Met- $\mathrm{Hb}$ formation and oxidative damage to erythrocyte membrane proteins and lipids (3). In several studies, we used DCI in erythrocytes as an index of oxidative stress in various adult and neonatal pathophysiological conditions (4-7). We found that RBC of hypoxic newborns have a higher DCI content $(6,7)$ and greater susceptibility to iron release after aerobic incubation 
than $\mathrm{RBC}$ of nonhypoxic newborns (5). In vitro experiments clearly showed that hypoxia was more significant than reoxygenation as a factor promoting iron release and $\mathrm{MetHb}$ formation in erythrocytes (8). During hypoxic incubation of partially oxygenated $\mathrm{Hb}$, the superoxide radical is formed and autoxidation of $\mathrm{Hb}$ occurs (9). Hypoxia also induces glycolytic hyperactivity and accumulation of 2,3-DPG (10).

It was recently reported that Tyr phosphorylation is implicated in the modification of several erythrocyte functions, including metabolic pathways (11), membrane transport (12), and cell volume and shape (13). Phosphorylation of proteins is a common characteristic of signal transduction systems. Immunoblotting with anti-pTyr antibodies of proteins separated by monodimensional SDS-PAGE has been widely used to study intracellular signaling pathways activated by extracellular stimuli (14). High-resolution 2-D SDS-PAGE in conjunction with 2-D immunoblot analysis with anti-pTyr antibodies enables several hundred Tyr-phosphorylated proteins to be studied at the same time (15).

In the present study, we assessed Tyr-phosphorylation proteins in normal and hypoxic RBC from newborns using advanced 2-D electrophoresis and computer-aided electrophoretogram analysis. We tested the hypothesis that a hypoxic environment and subsequent reoxygenation promote posttranslational changes in the RBC protein map of newborns, in addition to DCI release and MetHb formation. We used an in vitro model simulating $\mathrm{RBC}$ reoxygenation at birth after an intrauterine hypoxic event.

\section{MATERIALS AND METHODS}

Blood samples. Heparinized blood samples were obtained from the umbilical vein of five healthy full-term newborns, immediately after cord clamping. Gestational age ranged from 37 to $41 \mathrm{wk}$ and birth weight ranged from 2900 to $4200 \mathrm{~g}$. Informed consent was obtained from the parents. The study was approved by the Human Ethics Committee of the Medical Faculty of the University of Siena.

Erythrocyte incubation. After centrifuging at $600 \times g$ for $10 \mathrm{~min}$ at room temperature, plasma and buffy coats were removed. The erythrocytes were washed three times with $0.123 \mathrm{M} \mathrm{NaCl}, 28 \mathrm{mM}$ sodium phosphate/potassium phosphate buffer, $\mathrm{pH} 7.4$, and resuspended in the same buffer at $50 \%$ (vol/vol) as previously reported (16). To simulate the situation occurring in neonates at birth after an intrauterine hypoxic event (17), we used a model of hypoxiareoxygenation that consisted of incubating $\mathrm{RBC}$ without glucose under hypoxic conditions (exposed to a mixture of $4 \% \mathrm{O}_{2}, 6 \% \mathrm{CO}_{2}$, and $90 \% \mathrm{~N}_{2}$ ) for $16 \mathrm{~h}$ at $37^{\circ} \mathrm{C}$ and subsequently for $8 \mathrm{~h}$ under aerobic conditions. Control erythrocytes were incubated under aerobic conditions at $37^{\circ} \mathrm{C}$ for the period of the experiment, i.e. for $24 \mathrm{~h}$. All incubations were carried out in a shaker apparatus with antibiotics (20 units penicillin and $20 \mu \mathrm{g}$ streptomycin $/ \mathrm{mL}$ buffer). Samples were withdrawn at the indicated times for determination of DCI, MetHb (18), and hemolysis (16) and for 2-D PAGE (19). pH was measured in the erythrocyte suspension before and after incubation using a Radiometer ABL505 pH meter (Copenhagen, Denmark).

Erythrocyte DCI. DCI was determined as a DFO-iron complex, as previously reported (16). Briefly, at the end of incubation, $25 \mu \mathrm{M}$ DFO was added to samples. The erythrocytes were then hemolyzed by adding water ( $1 \mathrm{vol})$ and thawing from $-70^{\circ} \mathrm{C}$. The hemolysate was ultrafiltered in centrifugal filter devices (Centriplus YM-30; Amicon, Millipore, Bedford, MA) and the excess of DFO removed by silica column chromatography. The DFO-iron complex was determined by HPLC. HPLC conditions were as follows: 120-140 bars, flow rate $1.5 \mathrm{~mL} / \mathrm{min}$, silica column $5 \mu \mathrm{m}(250 \mathrm{~mm} \times 4 \mathrm{~mm})$, retention time 7-8 min.

Statistical analysis. Results were reported as means \pm SEM. Comparisons between groups were carried out by $t$ test. The value of $p<0.05$ was considered statistically significant.

High-resolution 2-D gel electrophoresis. Erythrocyte suspension $(200 \mu \mathrm{L})$ was withdrawn before incubation (time 0 ) and after 16 and $24 \mathrm{~h}$ of incubation and was centrifuged at $2500 \times g$ for $5 \mathrm{~min}$. 2-D gel electrophoresis was carried out on a 7- $\mu \mathrm{L}$ aliquot of erythrocyte pellet mixed with $483 \mu \mathrm{L}$ of a denaturing solution containing $8 \mathrm{M}$ urea, 4\% (wt/vol) 3-(3-cholamido propyl) dimethylammonio-1-propane sulfonate (CHAPS), $40 \mathrm{mM}$ Tris-base, $65 \mathrm{mM}$ DTE. Total protein assay was achieved by a standard procedure according to the method of Bradford (20). The quantity of erythrocyte proteins loaded for first dimension separation was $60 \mu \mathrm{g}$.

2-D electrophoresis was performed as described (21) using the Immobilinepolyacrylamide system (Amersham Biosciences AB, Uppsala, Sweden) Isolectric focusing (first dimension) was carried out on nonlinear wide-range immobilized $\mathrm{pH}$ gradients (IPG strips $\mathrm{pH} 3-10 ; 18 \mathrm{~cm}$-long) using the IPGphor system (Amersham Biosciences AB, Uppsala, Sweden). After electrophoresis, IPG strips were equilibrated for $12 \mathrm{~min}$ in $6 \mathrm{M}$ urea, $30 \%$ (vol/vol) glycerol, $2 \%$ (wt/vol) SDS, 0.05 M Tris- $\mathrm{HCl}, \mathrm{pH} \mathrm{6.8,2 \%} \mathrm{(wt/vol)} \mathrm{DTE,} \mathrm{and} \mathrm{subse-}$ quently for $5 \mathrm{~min}$ in the same urea/SDS/Tris buffer solution with $2.5 \%(\mathrm{wt} / \mathrm{vol})$ iodoacetamide instead of $2 \%(\mathrm{wt} / \mathrm{vol})$ DTE. The second dimension was carried out on $9-16 \%$ polyacrylamide linear gradient gels $(18 \mathrm{~cm} \times 20 \mathrm{~cm} \times 1.5 \mathrm{~mm})$ at $40 \mathrm{~mA} / \mathrm{gel}$ constant current and $10^{\circ} \mathrm{C}$ until the dye front reached the bottom of the gel (21). Gels were stained with ammoniacal silver nitrate as described (22).

Immunoblot analysis. After 2-D electrophoresis, proteins were electroblotted onto nitrocellulose membrane as described (23). Before immunodetection, membranes were reversibly stained with $0.2 \%$ (wt/vol) Ponceau $\mathrm{S}$ in $3 \%$ (wt/vol) trichloroacetic acid (TCA) for 3 min and spot position was marked to facilitate computer-aided matching of immunoreactive spots on the silverstained gels. Working dilution for mouse MAb to anti-pTyr (Santa Cruz Biotechnology, Santa Cruz, CA) was 1:1000. Immunoreactive spots were detected using goat anti-mouse $\mathrm{IgG}$ (working dilution 1:3000) conjugated with horseradish peroxidase (Bio-Rad, Hercules CA) and a chemiluminescence detection system (Amersham Pharmacia Biotech UK Ltd., Little Chalfont, $\mathrm{UK}$ ), according to the manufacturer's instructions.

Computer-aided image acquisition, data analysis, and protein identification. Electrophoretic images were digitized using a Molecular Dynamics (Amersham Biosciences AB, Uppsala, Sweden) computing densitometer (4000 $\times 5000$ pixels; 12 bits/pixel), and analyzed on a SUN SPARC station 10 with Melanie II (Bio-Rad Laboratories, Milan, Italy) software, which automatically detects, quantifies, and compares protein spots in digitized 2-D images.

Gel matching is a key operation in 2-D image analysis: it consists of comparing gel images and finding "pairs" of spots representing the same protein in both gels. The matching program Melanie II was also used for protein identification by comparison with 2-D reference maps (24).

Protein identification was based on matching electrophoretic coordinates (pI and $\mathrm{M}_{\mathrm{r}}$ directly related to amino acid composition) of spots on our map with known spots on a 2-D reference map of human red cells, available in the ExPASy World Wide Web molecular biology server of Geneva University Hospital and the University of Geneva (Switzerland).

\section{RESULTS}

DCI release and MetHb formation in newborn erythrocytes. DCI release and MetHb formation in newborn RBC exposed to hypoxia-reoxygenation or aerobic conditions (control) are reported in Table 1. Aerobic incubation was associated with progressive DCI release and MetHb formation. Hypoxic incubation for $16 \mathrm{~h}$ induced significantly higher DCI release than aerobic incubation for $16 \mathrm{~h}$. Reoxygenation for $8 \mathrm{~h}$, after $16 \mathrm{~h}$ of hypoxia, induced a further but nonsignificant increase in DCI. MetHb formation roughly paralleled iron release. No hemolysis or significant changes in $\mathrm{pH}$ were observed throughout the experiment.

2-D SDS-PAGE and immunoblot analysis. No substantial differences were observed among silver-stained 2-D SDSPAGE electrophoretograms of RBC of healthy newborns. Figure 1 shows a typical silver-stained 2-D electrophoretogram of RBC proteins. This electrophoretogram only shows proteins soluble in conventional denaturating solution. Membrane proteins, such as band 3 protein, were not present on 2-D PAGE maps, because they are not solubilized during sample preparation as previously reported (25). RBC soluble proteins were 
Table 1. DCI and MetHb in newborn erythrocytes exposed to aerobic incubation (control) and hypoxia-reoxygenation

\begin{tabular}{|c|c|c|c|c|c|}
\hline & \multicolumn{3}{|c|}{ Aerobic incubation (control) } & \multirow{2}{*}{$\begin{array}{c}\begin{array}{c}\text { Hypoxic } \\
\text { incubation }\end{array} \\
16\end{array}$} & \multirow{2}{*}{$\begin{array}{c}\begin{array}{c}\text { Hypoxia }+ \\
\text { reoxygenation }\end{array} \\
24(16+8)\end{array}$} \\
\hline Incubation time $(\mathrm{h})$ & 0 & 16 & 24 & & \\
\hline DCI $(\mathrm{nmol} / \mathrm{mL})$ & $1.5 \pm 0.28$ & $4.8 \pm 1.6$ & $12.3 \pm 1.4^{\bullet c}$ & $19.3 \pm 4.6^{\circ}$ & $24.3 \pm 0.9^{\circ} \mathrm{a}$ \\
\hline
\end{tabular}

The results (expressed as $\mathrm{nmol} / \mathrm{mL}$ of incubation mixture) are the means \pm SEM of five samples from full-term newborns.

$* p<0.0516 \mathrm{~h}$ hypoxic incubation $v s 16 \mathrm{~h}$ aerobic incubation.

$* * p<0.0216 \mathrm{~h}$ aerobic incubation vs 0 time.

${ }^{\circ} p<0.01^{\text {a }} 24 \mathrm{~h}$ hypoxia + reoxygenation $v s 24 \mathrm{~h}$ aerobic incubation; ${ }^{\mathrm{b}} 16 \mathrm{~h}$ hypoxic incubation $v s 16 \mathrm{~h}$ aerobic incubation; ${ }^{\mathrm{c}} 24 \mathrm{~h}$ aerobic incubation $v s 16 \mathrm{~h}$ aerobic incubation.

${ }^{*} p<0.00124 \mathrm{~h}$ hypoxia + reoxygenation $v s 24 \mathrm{~h}$ aerobic incubation.

$\mathrm{pH} 3.5$ non-linear IPG 3-10 $\mathrm{pH} 10$

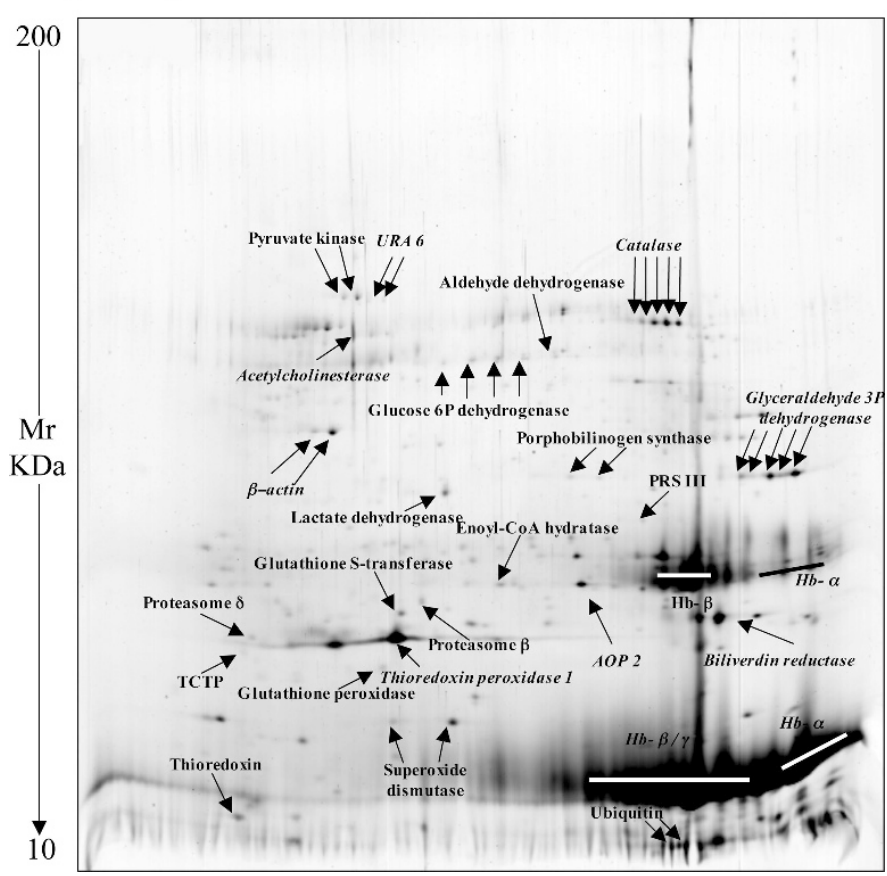

Figure 1. Typical 2-D silver-stained electrophoretogram of RBC proteins of healthy term newborn. Identified proteins are indicated.

identified by matching with a 2-D reference map of human RBC proteins using Melanie II software (24).

Different immunoreactivity patterns with the anti-pTyr antibody were observed between RBC incubated under aerobic and hypoxic/aerobic (reoxygenation) conditions. A few weakly immunoreactive proteins were observed in $\mathrm{RBC}$ at time 0 (catalase, glyceraldehyde 3-phosphate dehydrogenase, and $\alpha$, $\beta$ and $\beta / \gamma$ Hb chains, Fig. $2 A$ ), after 16 h (catalase, $\alpha, \beta$ and $\beta / \gamma \mathrm{Hb}$ chains, Fig. $2 B$ ), and after $24 \mathrm{~h}$ of aerobic incubation ( $\alpha, \beta$ and $\beta / \gamma \mathrm{Hb}$ chains, Fig. $2 C$ ). In contrast, many strongly immunoreactive proteins were observed after $16 \mathrm{~h}$ of hypoxic incubation (acetylcholinesterase, catalase, glyceraldehyde 3 -phosphate dehydrogenase, antioxidant protein 2 , biliverdin reductase, $\alpha, \beta$, and $\beta / \gamma \mathrm{Hb}$ chains, $\beta$-actin, URA 6 , and thioredoxin peroxidase 1) (Fig. 2D). After subsequent reoxygenation for $8 \mathrm{~h}$, five proteins (acetylcholinesterase, antioxidant protein 2, $\alpha, \beta$ and $\beta / \gamma \mathrm{Hb}$ chains, and URA 6) had decreased immunoreactive intensity and two proteins $(\beta$-actin and thioredoxin peroxidase 1) lost all immunoreactivity (Fig. $2 E$ ). Proteins disappearing from blots after further aerobic

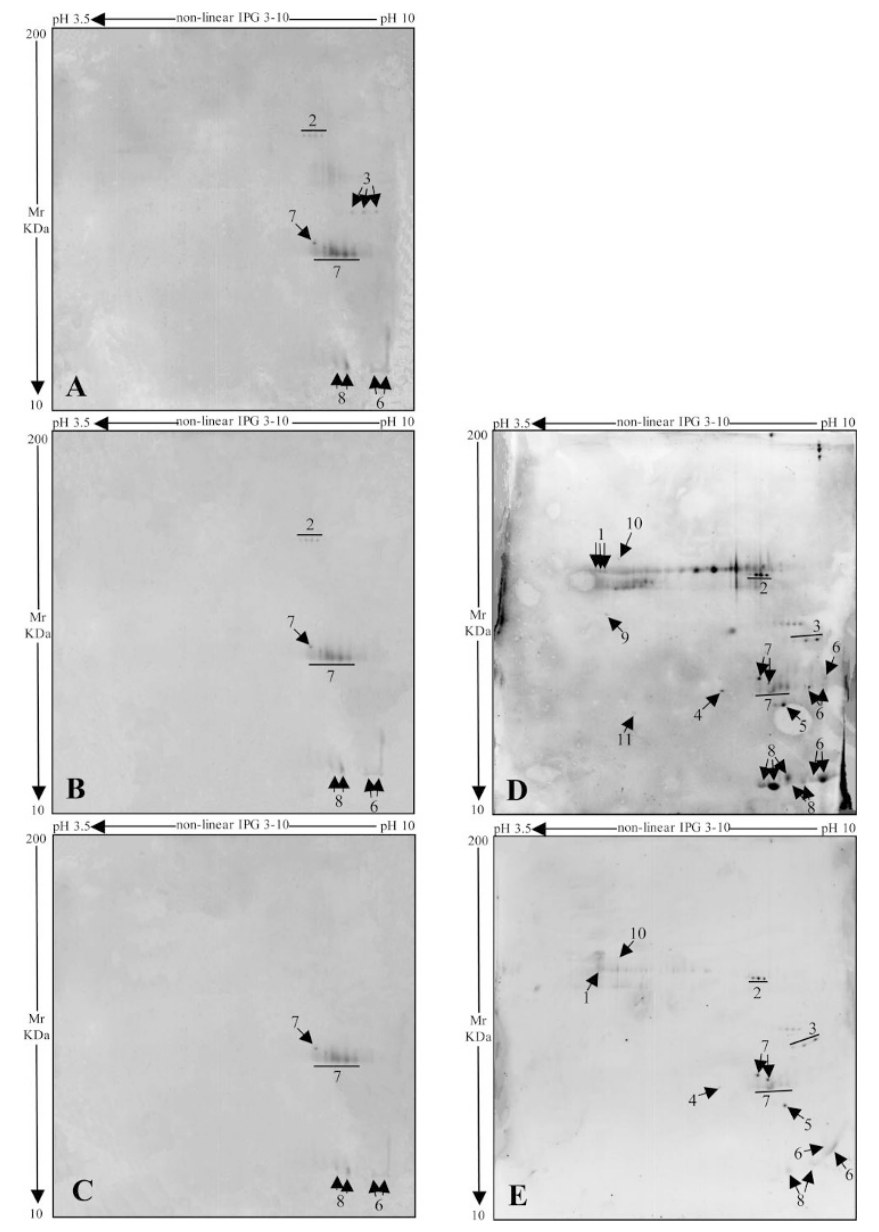

Figure 2. 2-D immunoblotting with anti-pTyr MAb of RBC. RBC from healthy term newborn before incubation $(A)$, and incubated for $16 \mathrm{~h}$ in aerobic conditions $(B)$, for $24 \mathrm{~h}$ in aerobic conditions $(C)$, for $16 \mathrm{~h}$ in hypoxic conditions $(D)$, and for $16 \mathrm{~h}$ in hypoxic and subsequently for $8 \mathrm{~h}$ in aerobic conditions $(E)$. Identified immunoreactive proteins are indicated by numbers (1: acetylcholinesterase, 2: catalase, 3: G3PDH, 4: AOP2, 5: BVR, 6: Hb $\alpha$-chain, 7: Hb $\beta$-chain, 8: Hb $\beta / \gamma$-chain, 9: $\beta$-actin, 10: URA 6, 11: Tpx 1).

incubation of RBC could be due to metabolization of these proteins as occurs in RBC aging (26). The different patterns of Tyr-phosphorylated proteins are shown in Table 2.

\section{DISCUSSION}

$\mathrm{RBC}$ were the first cells in which susceptibility of neonates to oxidative stress was demonstrated (5-7). In the present study, newborn RBC incubated under hypoxic condition 
Table 2. Presencelabsence of immunoreactivity of proteins in newborn RBC exposed to aerobic incubation (control) and hypoxia-reoxygenation

\begin{tabular}{|c|c|c|c|c|c|}
\hline \multirow{2}{*}{$\begin{array}{c}\text { Spot } \\
\text { list }\end{array}$} & \multicolumn{5}{|c|}{ Swiss } \\
\hline & Protein name & Prot AC & Time 0 & Control $16 \mathrm{~h}$ & $16 \mathrm{~h} \mathrm{Hx}$ \\
\hline 1 & AchE (precursor) & P22303 & - & - & + \\
\hline 2 & Catalase & P04040 & $+/-$ & $+1-$ & + \\
\hline 4 & AOP2 (antioxidant protein 2) & P32077 & - & - & + \\
\hline 5 & Biliverdin reductase (flavin reductase) & P32078 & - & - & + \\
\hline 6 & Hemoglobin $\alpha$-chain & P01922 & $+1-$ & $+1-$ & + \\
\hline & $\beta$-actin & $\begin{array}{l}\text { P02096 } \\
\text { P02570 }\end{array}$ & & _ & + \\
\hline 9 & 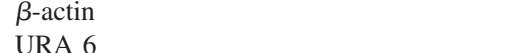 & & - & - & $\begin{array}{l}+ \\
+\end{array}$ \\
\hline 10 & $\begin{array}{l}\text { URA } 6 \\
\text { Thioredoxin peroxidase } 1 \text { (NKFF-B) }\end{array}$ & $\begin{array}{l}\text { P32080 } \\
\text { P } 32119\end{array}$ & - & - & $\begin{array}{l}+ \\
+1-\end{array}$ \\
\hline 11 & Thioredoxin peroxidase 1 (NKEF-B) & P32119 & - & - & $+1-$ \\
\hline
\end{tabular}

Swiss Prot AC, accession number to retrieve documentation on corresponding protein from Swiss Prot database (http:www.expasy.org); $H x$, hypoxia; $N x$, normoxia.

showed higher DCI release and MetHb formation than RBC incubated under aerobic conditions, as expected. Reoxygenation of hypoxic erythrocytes induced a further but not significant increase in iron release. These results are in line with previous in vivo studies in which we found higher DCI release and MetHb formation in RBC of hypoxic than normoxic babies (5-7) and they confirm that hypoxic environments are a factor promoting iron release. Because iron release is related to oxidative stress, hypoxia paradoxically seems to be a condition of oxidative stress.

Because PTK is abundant in RBC (11), we investigated Tyr-phosphorylated components of the RBC protein map. We tested the hypothesis that a hypoxic environment and subsequent reoxygenation promote post-translational changes in the newborn RBC protein map. This was suggested by oxidative stress occurring in our in vitro model simulating the perinatal hypoxia-reperfusion event. It has also been suggested that ROS may interfere with intracellular signalling pathway, switching on Tyr-phosphorylation (27), and, as mentioned above, that the superoxide radical is formed under hypoxic conditions (9).

Proteomics is a powerful procedure for investigating complex processes in cells and tissues. Reversible protein tyrosine phosphorylation is a widespread mechanism of modulation of protein/enzyme activity. Protein phosphorylation is the principal mechanism controlling the rate of metabolic enzyme pathways. Phosphate is a negatively charged residue that interacts with proteins to create a conformational change that switches protein activity on and off. Most enzymes regulated by phosphorylation have multiple phosphorylation sites. For some enzymes, the phosphorylation sites are antagonistic, for others they are synergistic, and phosphorylation at one site may act synergistically with phosphorylation at another site.

Our results showed different immunoreactivity patterns in newborn RBC incubated under aerobic and hypoxic conditions. All immunoreactive proteins identified by immunoblot in the RBC protein map were Tyr-phosphorylated after $16 \mathrm{~h}$ of hypoxic incubation. Some are involved in cell defence against hypoxia, such as G3PDH (glycolytic enzyme) or against oxidative stress, such as catalase, AOP2, BVR, and Tpx 1.

What this means is debatable. Indeed, although chemiluminescent detection did not enable precise quantification, the changes we observed in the RBC protein map after hypoxic incubation may be explained as a defensive reaction of neonatal RBC against ROS. In another study, we reported that hypoxia remodels the signaling pathway by switching on Tyrphosphorylation of some proteins (28).

Studies by Zylinska et al. (29) have provided some evidence of a potential role of asphyxia in disrupting phosphorylation processes in newborn erythrocytes, as reflected by altered protein kinase activities in erythrocyte membranes of asphyxiated newborns.

We do not know whether Tyr-phosphorylation means activation or deactivation, but phosphorylation of G3PDH strongly suggests a hypoxia-induced increase in enzyme activation. A major substrate for human erythrocyte PTK is reported to be the anion transporter band 3 protein (11). G3PDH is associated reversibly with the $\mathrm{N}$-terminus of the cytoplasmic domain of band 3 (30). Once the enzyme is bound, it is totally inhibited; on release, however, it is restored to full activity. Control of the G3PDH binding site and consequently glycolytic flux through this control point is achieved by phosphorylation of Tyr 8 and Tyr 21 at the G3PDH binding site on band 3. Phosphorylation blocks enzyme binding, activating G3PDH. Other authors have observed that deoxygenation increases the degree of Tyr phosphorylation of band 3 in RBC (31) with an increase in glycolytic enzyme activities (11). Gonzalez et al. (32) observed that exposure to hypobaric hypoxia followed by reoxygenation induced inhibition of band 3 anion transport function and a decrease in binding of G3PDH to band 3. In the present study, we observed increased G3PDH Tyr-phosphorylation in neonatal RBC samples after $16 \mathrm{~h}$ of hypoxic incubation as well as after $8 \mathrm{~h}$ of reoxygenation with respect to starting level at time 0 . No G3PDH Tyr-phosphorylation was observed in samples after aerobic incubation (Table 2). Phosphorylated G3PDH, released by band 3 protein, consequent to hypoxia, may therefore enhance glycolysis.

New types of antioxidant proteins have recently been reported in RBC and other cells: the thiol-specific antioxidant proteins or as recently renamed, Prxs (33). Prxs detoxify alkyl-hydroperoxides, peroxynitrates, and hydrogen peroxides using reducing equivalents from thiol-containing molecules, such as thioredoxins and glutathione. In addition to their 
antioxidant activity, Prxs have been implicated in a number of cellular functions such as cell proliferation and differentiation, neuronal apoptosis, protection of radical-sensitive proteins, heme metabolism, and intracellular signaling. Prxs may be regulated by changes in phosphorylation, redox, and possibly oligomerization state (33). Six subclasses of mammal Prxs (Prx I-VI) are considered.

Prx VI (AOP2) and Prx II (Tpx1) are members of this protein family. Stuhlmeier et al. (34) have demonstrated that AOP2 is a cytoplasmic protein found in lymphocytes, endothelial cells, and RBC. It protects RBC from ROS in a dosedependent manner by binding to $\mathrm{Hb}$, particularly to heme, thus preventing induced and spontaneous oxidation to MetHb. Heme is the prosthetic group of several proteins and enzymes (such as myoglobin, cytochrome $c$ and cytochrome P450, and others), and AOP2 may protect them also. This would explain its nearly ubiquitous presence and provide further evidence of its importance as a major protective protein.

We observed that AOP2 was Tyr-phosphorylated after hypoxia (Table 2), when DCI release and MetHb formation are high (Table 1), suggesting that hypoxia induces Tyrphosphorylation which presumably leads to a change in antioxidant function with consequent oxidation of $\mathrm{Hb}$. Tyrphosphorylation could also involve the $\alpha, \beta$, and $\gamma$ chains of $\mathrm{Hb}$ that are more Tyr-phosphorylated under hypoxia than normoxia.

Tpx 1 is another antioxidant protein that limits the activity of ROS. Studies by Ichimiya et al. (35) showed that mouse Tpx had broad tissue distribution, but that its expression was especially marked in cells very active in metabolizing oxygen molecules, such as erythroid cells, renal tubule cells, heart and skeletal muscle cells, and certain types of neurons. Increased expression of Tpx has been observed in areas of the brain most susceptible to hypoxic-ischemic injury in humans. The authors proposed that Tpx contributes to antioxidant defense in erythrocytes and neurons by limiting the destructive capacity of oxygen radicals. Lee et al. (36) showed that Prx $\mathrm{II}^{-1-}$ mice have hemolytic anemia and that Prx II plays a major role in protecting RBCs from oxidative stress in mice. In our samples, Tpx 1 was partially Tyr-phosphorylated after $16 \mathrm{~h}$ of hypoxia, suggesting that its phosphorylation may increase, counteracting hypoxia-induced stress. No Tyr-phosphorylation was observed after reoxygenation.

Catalase occurs in almost all aerobic organisms and is an important factor of cellular defence against hydrogen peroxide $\left(\mathrm{H}_{2} \mathrm{O}_{2}\right)$. One antioxidant role of catalase is to lower the risk of hydroxyl radical formation from $\mathrm{H}_{2} \mathrm{O}_{2}$ via the Fenton-reaction catalyzed by $\mathrm{Cu}$ or $\mathrm{Fe}$ ions. Recent in vitro studies by $\mathrm{Cao}$ et al. (37) have proven that Tyr-phosphorylation is required for catalase activation and thereby degradation of $\mathrm{H}_{2} \mathrm{O}_{2}$. In our experiments, we found that catalase is Tyr-phosphorylated. According to Cao et al., this could mean an increase in antioxidant defences as a consequence of DCI release after hypoxic incubation and reoxygenation.

Studies by Shalloe et al. (38) show that human BVR and FR, isolated from bovine erythrocytes, are identical. Human FR catalyzes the NADPH-dependent reduction of flavin-mononucleotide and methylene blue and, in the presence of redox couplers, reduction of MetHb. FR has been shown to be identical with a major RBC protein of unknown function termed "green heme-binding" protein, found in erythrocytes and liver (39). BVR may therefore have a role in protecting cells from oxidative damage. In our experiments, BVR was not Tyr-phosphorylated during aerobic incubation, when MetHb formation was low (Table 1), but it was Tyr-phosphorylated after hypoxia and hypoxia-reoxygenation, when concentrations of MetHb were higher than during aerobic incubation. This suggests that Tyr-phosphorylation may induce changes in enzyme activity.

$\mathrm{AChE}$, a key component of cholinergic transmission, is responsible for the Yt blood group system. A recent study suggests that $\mathrm{AChE}$ is an excellent enzyme marker for ageing of human RBC (26). We observed that AChE was Tyrphosphorylated after $16 \mathrm{~h}$ of hypoxia, when DCI release is high, as it is in erythrocyte aging (3), suggesting that Tyrphosphorylation could modify enzyme activity.

In our study, another protein Tyr-phosphorylated after $16 \mathrm{~h}$ of hypoxia was URA6. URA6 is a fragment of a RBC protein of unknown function.

Beta-actin is an isoform of actin protein. Three main groups of actin isoforms, alpha, beta, and gamma, have been identified. Alpha actins are found in muscle and are a major constituent of the contractile system. Beta and gamma actin isoforms coexist in most cell types as components of the cytoskeleton and as mediators of internal cell motility. One of the many targets of tyrosine kinase-mediated signaling pathways is the actin cytoskeleton. Actin cytoskeletal rearrangements are important fundamental events that occur during a variety of cellular processes (40). Beta-actin is Tyr-phosphorylated after $16 \mathrm{~h}$ of hypoxia in RBC of newborns, which suggests that hypoxia could induce cytoskeletal reorganization.

In conclusion, high-resolution 2-D gel electrophoresis of neonatal RBC incubated under hypoxic conditions revealed a complex pattern of Tyr-phosphorylation in the protein map. Hypoxia may possibly increase Tyr-phosphorylation of antioxidant proteins in RBC of newborns. We hypothesize that this increase is a cellular response of neonatal $\mathrm{RBC}$ to oxidative stress. To our knowledge, this is the first report describing the 2-D map of Tyr-phosphorylated soluble proteins of neonatal RBC after hypoxia. These findings may help to understand the molecular events underlying hypoxia-induced modification of neonatal RBC. As observed in brain tissue (28), similar mechanisms could be implicated in perinatal hypoxic-ischemic damage of other cells. Further research using different methodologies is needed to clarify overall membrane protein expression in $\mathrm{RBC}$ of newborns.

\section{REFERENCES}

1. Ryan TP, Aust SD 1992 The role of iron in oxygen-mediated toxicities. Crit Rev Toxicol 22:119-141

2. Minotti G 1993 Sources and role of iron in lipid peroxidation. Chem Res Toxicol 6:134-146

3. Comporti M, Signorini C, Buonocore G, Ciccoli L 2002 Iron release, oxidative stress and erythrocyte ageing. Free Radic Biol Med 32:568-576

4. Ciccoli L, Signorini C, Scarano C, Rossi V, Bambagioni S, Ferrali M, Comporti M 1999 Iron release in erythrocytes from patients with $\beta$-thalassemia. Free Radic Res 30:407-413

5. Ciccoli L, Rossi V, Leoncini S, Signorini C, Paffetti P, Bracci R, Buonocore G, Comporti M 2003 Iron release in erythrocytes and plasma non protein-bound iron in hypoxic and non hypoxic newborns. Free Radic Res 37:51-58 
6. Buonocore G, Zani S, Sargentini I, Gioia D, Signorini C, Bracci R 1998 Hypoxiainduced free iron release in the red cells of newborn infants. Acta Paediatr 87:77-81

7. Buonocore G, Zani S, Perrone S, Caciotti B, Bracci R 1998 Intraerythrocyte nonprotein-bound iron and plasma malondialdehyde in the hypoxic newborn. Free Radic Biol Med 25:766-770

8. Ciccoli L, Rossi V, Leoncini S, Signorini C, Blanco-Garcia J, Aldinucci C, Buonocore G, Comporti M 2004 Iron release, superoxide production and binding of autologous IgG to band 3 dimers in newborn and adult erythrocytes exposed to hypoxia and hypoxia-reoxygenation. Biochim Biophys Acta 1672:203-213

9. Balagopalakrishna C, Manoharan PT, Abugo OO, Rifkind JM 1996 Production of superoxide from hemoglobin-bound oxygen under hypoxic conditions. Biochemistry 35:6393-6398

10. Arnaud J, Gutierrez N 1984 Human red cell glycolysis in high altitude chronic hypoxia. Am J Phys Anthropol 63:307-314

11. Harrison ML, Rathinavelu P, Arese P, Geahlen RL, Low PS 1991 Role of band 3 tyrosine phosphorylation in the regulation of erythrocyte glycolysis. J Biol Chem 266:4106-4111

12. De Franceschi L, Fumagalli L, Olivieri O, Corrocher R, Lowell CA, Berton G 1997 Deficiency of Src family kinases Fgr and Hck results in activation of erythrocyte $\mathrm{K} / \mathrm{Cl}$ cotransport. J Clin Invest 99:220-227

13. Bordin L, Clari G, Moro I, Dalla Vecchia F, Moret V 1995 Functional link between phosphorylation state of membrane proteins and morphological changes of human erythrocytes. Biochem Biophys Res Commun 213:249-257

14. Thannickal VJ, Aldweib KD, Fanburg BL 1998 Tyrosine phosphorylation regulates $\mathrm{H}_{2} \mathrm{O}_{2}$ production in lung fibroblasts stimulated by transforming growth factor beta 1 . J Biol Chem 273:23611-23615

15. Godovac-Zimmermann J, Soskic V, Poznanovic S, Brianza F 1999 Functional proteomics of signal transduction by membrane receptors. Electrophoresis 20:952-961

16. Ferrali M, Ciccoli L, Comporti M 1989 Allyl alcohol-induced hemolysis and it relation to iron release and lipid peroxidation. Biochem Pharmacol 38:1819-1825

17. Bloom RS 1997 Delivery room resuscitation of the newborn. In: Fanaroff AA, Martin RJ, eds Neonatal-Perinatal Medicine: Diseases of the Fetus and Infant. CV Mosby, St. Louis, MO, pp 376-402

18. Evelyn KA, Malloy HT 1938 Microdetermination of oxyhemoglobin, methemoglobin and sulfhemoglobin in a single sample of blood. J Biol Chem 126:655-662

19. Bjellqvist B, Pasquali C, Ravier F, Sanchez JC, Hochstrasser D 1993 A nonlinear wide-range immobilized $\mathrm{pH}$ gradient for two-dimensional electrophoresis and its definition in a relevant $\mathrm{pH}$ scale. Electrophoresis 14:1357-1365

20. Bradford MM 1976 A rapid and sensitive method for the quantification of microgram quantities of protein utilizing the principle of protein-dye binding. Anal Biochem $72: 248-254$

21. Hochstrasser DF, Harrington MG, Hochstrasser AC, Miller MJ, Merril CR 1988 Methods for increasing the resolution of two-dimensional protein electrophoresis. Anal Biochem 173:424-435

22. Hochstrasser DF, Patchornik A, Merril CR 1988 Development of polyacrylamide gels that improve the separation of proteins and their detection by silver staining. Anal Biochem 173:412-423

23. Towbin H, Staehelin T, Gordon J 1979 Electrophoretic transfer of proteins from polyacrylamide gels to nitrocellulose sheets: procedure and some applications. Proc Natl Acad Sci U S A 76:4350-4354
24. Appel RD, Palagi PM, Walther D, Vargas JR, Sanchez JC, Ravier F, Pasquali C, Hochstrasser DF 1997 Melanie II-a third-generation software package for analysis of two-dimensional electrophoresis images: I. Features and user interface. Electrophoresis 18:2724-2734

25. Rabilloud T, Adessi C, Giraudel A, Lunardi J 1997 Improvement of the solubilization of proteins in two-dimensional electrophoresis with immobilized $\mathrm{pH}$ gradients. Electrophoresis 18:307-316

26. Prall YG, Gambhir KK, Ampy FR 1998 Acetylcholinesterase: an enzymatic marker of human red blood cell aging. Life Sci 63:177-184

27. Brumell JH, Burkhardt AL, Bolen JB, Grinstein S 1996 Endogenous reactive oxygen intermediates activate tyrosine kinases in human neutrophils. J Biol Chem 271:1455-1461

28. Buonocore G, Liberatori S, Bini L, Mishra OP, Delivoria-Papadopoulos M, Pallini V, Bracci R 1999 Hypoxic response of synaptosomal proteins in term guinea pigs fetuses. J Neurochem 73:2139-2148

29. Zylinska L, Sobolewska B, Gulczynska E, Ochedalski T, Soszynski M 2002 Protein kinases activities in erythrocyte membranes of asphyxiated newborns. Clin Biochem 35:93-98

30. Low PS, Geahlen RL, Mehler E, Harrison ML 1990 Extracellular control of erythrocyte metabolism mediated by a cytoplasmic tyrosine kinase. Biomed Biochim Acta 49:S135-S140

31. Barbul A, Zipser Y, Nachles A, Korenstein R 1999 Deoxygenation and elevation of intracellular magnesium induce tyrosine phosphorylation of band 3 in human erythrocytes. FEBS Lett 455:87-91

32. Gonzalez G, Celedon G, Sandoval M, Gonzalez GE, Ferrer V, Astete R, Behn C 2002 Hypobaric hypoxia-reoxygenation diminishes band 3 protein functions in human erythrocytes. Pflugers Arch 445:337-341

33. Wood ZA, Schröder E, Robin Harris J, Poole LB 2003 Structure, mechanism and regulation of peroxiredoxins. Trends Biochem Sci 28:32-40

34. Stuhlmeier KM, Kao JJ, Wallbrandt P, Lindberg M, Hammarström B, Broell H, Paigen B 2003 Antioxidant protein 2 prevents methemoglobin formation in erythrocyte hemolysates. Eur J Biochem 270:334-341

35. Ichimiya S, Davis JG, O'Rourke DM, Katsumata M, Greene MI 1997 Murine thioredoxin peroxidase delays neuronal apoptosis and is expressed in areas of the brain most susceptible to hypoxic and ischemic injury. DNA Cell Biol 16:311321

36. Lee TH, Kim SU, Yu SL, Kim SH, Park do S, Moon HB, Dho SH, Kwon KS, Kwon HJ, Han YH, Jeong S, Kang SW, Shin HS, Lee KK, Rhee SG, Yu DY 2003 Peroxiredoxin II is essential for sustaining life span of erythrocytes in mice. Blood 101:5033-5038

37. Cao C, Leng Y, Kufe D 2003 Catalase activity is regulated by c-Abl and Arg in the oxidative stress response. J Biol Chem 278:29667-29675

38. Shalloe F, Elliott G, Ennis O, Mantle TJ 1996 Evidence that biliverdin-IX $\beta$ reductase and flavin reductase are identical. Biochem J 316:385-387

39. Xu F, Quandt KS, Hultquist DE 1992 Characterization of NADPH-dependent methemoglobin reductase as a heme-binding protein present in erythrocytes and liver. Proc Natl Acad Sci U S A 89:2130-2134

40. Jamora C, Fuchs E 2002 Intercellular adhesion, signalling and the cytoskeleton. Nat Cell Biol 4:E101-E108 